\title{
ANALYSIS OF THE KEY SUCCESS FACTORS FOR COMMERCIALIZING INNOVATION
}

\author{
Pemila Mawaddah*1 | Huang Bang-Ning ${ }^{1}$ | Chang Chin-Hsin ${ }^{2}$
}

\footnotetext{
${ }^{1}$ Dept. of Business Administration, National Yunlin University of Science and Technology, Yunlin, Taiwan

${ }^{2}$ For More Maker Space, Yunlin, Taiwan
}

\section{Correspondence \\ *Pemila Mawaddah, Dept of Business Administration, National Yunlin University of Science and Technology, Yunlin, Taiwan. Email: pemilamawaddah@gmail.com}

\section{Present Address}

National Yunlin University of Science and Technology, 123 University Road, Section 3, Douliou, Yunlin County 64002, Taiwan

\begin{abstract}
The development and commercialization of new technologies have inherent uncertainties and associated risks. Many researches conducted by Indonesian R\&Ds never reached the diffusion stage, i.e., the commercialization process. Therefore, Indonesia needs a strategy to translate promising technologies into a stream of economic returns for its stakeholders. This study analyzes the critical success factors (KSF) for commercializing innovation. It used new product development literature and TOE (technology-organization-environment) framework and developed a research model to investigate the determinants of commercialization of innovation. In choosing the selected vital success factors, a hierarchy of KSFs was defined. It also used the Analytic hierarchy process to help experts rank the importance of identified KSFs. The KSF hierarchy is constructed with two levels: a critical comprising three dimensions and a detailed level of nine individual factors. The result shows that the experts believe that in the top-level, technology is the most critical dimension followed by environment and organization. Technology is the primary consideration for the company before launching their product to the market. Market demand has the highest rank from the environmental dimension. Lastly, experts suggest that the organization network is the most significant to grasp investors and potential markets for successful commercialization.
\end{abstract}

\section{KEYWORDS:}

Author Guidelines, Literature Study, Original Research, Template

\section{1 | INTRODUCTION}

In the era of globalization, technological innovation is one of the main drivers of success in winning the global competition. Previous studies have reported that new products produced by new technologies have resulted in a $40 \%$ to $90 \%$ increase in national wealth in most countries. Indonesia is one of the developing countries that intensively emphasized technology as a part 
of the sustainable process of their national development. Hill (1998) mentioned that Indonesia needs technology to sustain its economic growth ${ }^{[1]}$.

As mentioned in Indonesia's National Medium Term Development Plan or Rencana Pembangunan Jangka Menengah Nasional (RPJMN) 2015-2019, one of the government missions is to realize a competitive nation. This mission can be achieved through the development and application in the industry to produce competitive products. Therefore, the direction of Indonesia's national development 2015-2019 is to build a competitive advantage of the economy based on natural resources, qualified human resources, and the ability of science and technology. Indonesian government Ministry of Research, Technology, and Higher Education (RISTEKDIKTI) encourages domestic firms to build their technology by giving them Technological Incentives in Industry since 2015.

However, currently, Indonesia's competitiveness rating has declined based on the data from the International Institute of Management Development (IMD) in 2016. Indonesia's competitiveness ranking fell by 6th place, from 42th to 48th. Then according to the World Economic Forum (WEF) in 2016, Indonesia's rank dropped from 34th to 37th out of 140 countries. Another data, according to the Global Innovation Index (GII) in August 2016 Indonesia is at 88th position from 128th countries. This condition is undoubtedly a challenge for Indonesia, given the potential both in terms of natural resources and one of the largest populations in the world. One of the problems encountered, many research activities conducted by national R\&D, only reached the alpha test stage (prototype development, replication and laboratory test) and beta (field test and further development) but not yet stages of diffusion. These diffusion stages are the resulting technology already implemented by the user, the initiation of commercialization, market development, and further commercialization. At this stage, various processes are required to meet the standards in accordance with market demand. The most challenging problem facing firms is how the new product or technology successfully commercialized, given a high level of market uncertainty. The experience proved that the commercialization of technology is potentially linked to levels of uncertainty and risk ${ }^{[2] 6]}$.

Most studies have emphasized the significant role of market research, which includes market, customer, and competitor analysis in stimulating the need for a new product $7+9]$. Despite the importance of this research subject, existing empirical results are often very varied and fragmented $[10[12]$.

Moreover, few efforts have been made to rank KSFs based on their relative importance [13]. This limited understanding is partly because of the complexity of the topic, and partly due to the researchers' choice of methodology ${ }^{[14}$. Furthermore, previous research in this domain has tended to focus on the operations of large and well-established firms based in developed countries. It is unclear whether these findings would also hold in emerging countries such as Indonesia.

In this article, we aim to contribute towards simplifying the variations of the aforementioned success factors. This simplification is achieved by adopting a systematic approach using the Technology-Organization-Environment (TOE) framework and adapts its commercialization of innovation. In doing so, it offers an integrated view and conceptual guidelines for examining the determinants of success factors in the context of the high-tech industry ${ }^{[15]}$.

To achieve this goal, this study was conducted in three phases. In the first phase, a preliminary list of factors associated with the success of the high-tech industry was identified through a comprehensive literature review. These factors are further modified and validated through interviews with academicians and experts in the selected industry. However, these success factors are interconnected and cannot be treated as independent factors. Because of these interdependencies, the less critical factors may turn out to be more significant when evaluated collectively [16. To address this issue, in the second phase, we propose the use of the Analytic Hierarchy Process (AHP) method to obtain the weight distribution of success factors and identify the KSFs.

AHP proves to be a practical approach for assessing the models with complex interdependent factors and provides a rigorous basis for addressing the problems involving both quantitative and qualitative factors ${ }^{[17]}$. AHP is a simple yet powerful tool that was first developed within the management science field over 20 years ago ${ }^{18}$. The relative weights of the KSFs obtained in the second phase are used as inputs for the third phase. In the last stage, we propose the results of AHP on KSFs as criteria for evaluating performance. The proposed approach is applied to two high-tech industries in Indonesia. The two selected high-tech sectors in Indonesia are pharmaceutical and petroleum. 


\section{2 | RELATED WORKS}

In almost all cases, the successful innovation commercialization requires that the know-how in question be utilized with other capabilities or asset 19 . Key success factors use as a planning tool. The planning school aims at developing planning instruments which help businesses in finding the right strategy. The main assumption is that by providing input which helps decision-makers in structuring their thoughts, the quality of decision-making can be improved [20]. Successful commercialization is crucial in transforming invention into innovation ${ }^{[22}$. Based on prior research, a wide variety of antecedent factors can influence the outcomes of innovation activity. The diversity of research in this field includes marketing, organizational, behavior, engineering, and operation management ${ }^{233}$.

\section{1 | Key Success Factors of Innovation Commercialization}

In this part, we collected the previous study that mentioned success factors for innovation commercialization. After summarizing the factors, then we composed categories based on the TOE framework. Categorizing into the TOE framework is very helpful in many simplified factors presented from the previous study. As the ground theory, Project SAPPHO ${ }^{[24}$ is probably the first study to analyze successful commercial innovation by comparing between successful and unsuccessful innovations; after the study, the dyadic comparisons between project successes and failures have become popular to discover principal discriminating factors of innovation commercialization [17] 25]. The SAPPHO study found five main factors of commercially successful innovations, i.e., a better understanding of user needs, more marketing and publicity, work efficiently, use technology and scientific advice, and responsible individual.

Following the SAPPHO project, Cooper (1980) identified three success factors: the degree product uniqueness and superiority compared to existing alternatives. The second most important factor is market knowledge and the feeling of future market development. The third one is the synergy of the technological and manufacturing resource. Moreover, Teece (1986) indicated that services such as marketing, competitive manufacturing, and after-sales support were almost always needed for successful innovation commercialization. Cooper and Kleinschmidt (1987) further suggested that the market environment of new product success was determined by the new product strategy and development process execution. Additionally, the studies conducted by Montoya-Weiss and Calantone (1994); Henard and Szymanski (2001)and Van der Panne, et al. (2003) grouped various key success factors into multiple categories. Montoya-Weiss and Calantone (1994) categorize key factors into strategy, process, organization, and market. Henard and Szymanski (2001) categorize key factors into product, strategy, process, and market. Van der Panne et al. (2003) categorizes key factors into product, firm, project, and market.

For technology commercialization, technology competitiveness is the most important factor ${ }^{[26}$. Balachandra and Friar (1999) pointed out that the more innovative technology is, the more likely is it to allow customers to do something beneficial through a greater breadth of technologies embodied in new products. R\&D capability factors are also considered critical factors for improving the likelihood of new product success $26+30$. R\&D capabilities factors are generally related to firms' resource allocation and organizational climate-related to the commercialization process. If the commercialization process and R\&D organization are well-organized, the technologies used in the development of the project would also be widely available to the organization.

Souder and Song (1998) argued that organizational factors such as experiences, know-how, and professionalism of employees are related to the improvement of new product development capabilities. R\&D employees should have a broad spectrum of experience and expertise in the design and implementation of new technology products.

Furthermore, management should enhance employees on R\&D capabilities by creating a supportive climate that helps increase the innovation capability through rewards and internal support to employees. Managers set directions and develop clear commercialization processes that empower employees' productivity and competence in developing a new product 31 .

Based on the previous literature, technology and R\&D capabilities should also be applied and adapted to improve the likelihood of success of new technology products. The two industries may have different characteristics of success factors. However, based on previous studies $[23]$ 24], many success factors in commercializing an innovation was conducted in multi-industry. It may be possible as the different industry competes for the same market or have the same characteristics. In this study, the pharmaceutical and petroleum industry carry the same characteristic, which contributes significantly to high-tech industry market performance in Indonesia. 


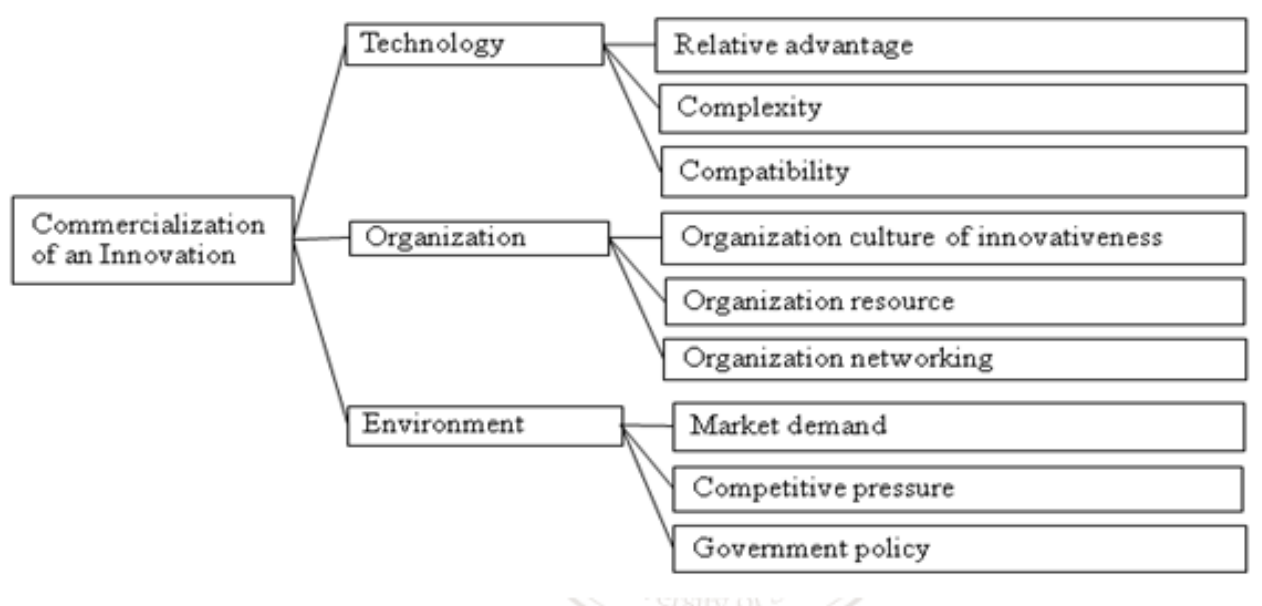

FIGURE 1 The TOE framework.

\section{2 | TOE Framework}

Tornatzky and Fleischer proposed the technology-organization-environment (TOE) framework in 1990. The framework, as shown in Figure 1, explained the complete process of innovation from the development of innovation by engineers and entrepreneurs to the adoption and implementation of those innovations from the aspects of technology, organization, and environment context ${ }^{[32]}$. The technological context refers to technological attributes relevant to innovation. The organizational context refers to the characteristics of the firm, including its size, its resources, and the complexity of its managerial structure. The environmental context refers to the arena in which a firm conducts its business; the arena in question may include the firm's belonging industry, its customers, its competitors, and the government 33 .

The TOE framework has a solid theoretical basis, consistent empirical support, and potential of the application, though specific factors identified within the three contexts may vary across different studies ${ }^{[34}$. For example, Chau and Tam (1997) adopted this framework. They identified three factors that affect the adoption of open systems, namely, the characteristics of the innovation, organizational technology, and the external environment. Meanwhile, Borgman et al. (2013) used the TOE framework to investigate the factors influencing cloud computing adoption. In this study, the TOE framework is pursued to conceptualize and understand how IT governance processes and structures moderate those factors. Lastly, Pan and Jang (2008) considered the TOE framework to examine the effect of the decision to adopt enterprise resource planning (ERP) in Taiwan's communications industry by identifying factors that distinguish adopters from non-adopters. To construct the TOE framework, the considering factors concerning the successful innovation commercialization were deliberately drawn from a set of related theories and prior research 17$] 23]$ 35. Those factors are described in the following sections.

\section{3 | Technological Context}

The technological context represents the pool of technological attributes of innovation for its adoption. These can be both the technologies available to the market and the firm's' current technological assets. In other words, the decision to adopt an innovation depends not only on what is available on the market but also on how such innovation fit with the technologies that a firm already possesses $[17[25$.

The literature highlighted the importance of technology to the success of innovation commercialization. For example, Gatignon et al. ${ }^{[7}$ pointed out that the role of technology appeared unconditional; more is better in any kind of market, even in a stable market. Henard and Szymanski ${ }^{[35]}$ and Van der Panne et al. [17] argued that technology was the nature of product innovation; Khademi and Ismail (2013) emphasized the technology employed in the process innovation development. Montoya-Weiss and Calantone ${ }^{[23]}$ asserted the synergy between technology implementation and the strategic positioning of an innovation. 
The technological context established in the current study has its origins in Innovation Diffusion Theory (IDT) 36 . The IDT proposes five perceived attributes of an innovation that influence its adoption: relative advantage, compatibility, complexity, trialability, and observe ability. However, empirical studies have indicated that, of these five attributes, only relative advan-

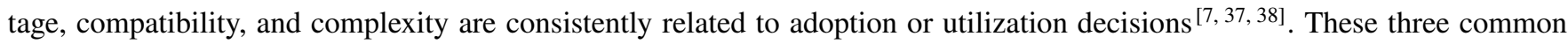
attributes are echoed by prior innovation commercialization research. How relative advantage, compatibility, and complexity of an innovation related to the innovation commercialization is explored as follows.

\section{4 | Relative advantage}

Relative advantage is defined as the degree to which an innovation is perceived as better than the idea it supersedes 39.40$]$. These attributes are often expressed in economic profitability, in status giving, or other ways. The nature of the innovation largely determines what specific type of relative advantage (such as financial, social, and the like). Relative advantage relies on the matter of individual feel the innovation give benefits, The higher the perceived relative advantage of innovation, the more rapid its rate of adoption is going to be ${ }^{39}$. Relative advantage appears as a consistently important characteristic for innovation success.

A large-scale meta-analysis study by ${ }^{[23]}$ showed a significant correlation between successful commercialization and the advantages of innovation. Consumers need to be convinced of the potential benefit of innovation 39 . New products that are more continuous, product superiority is relevant for success, although it probably needs to be less overwhelming since customers face a much lower purchase risk $\left.{ }^{39} 41\right]$. In the services industry, the need for product superiority or distinctiveness has also been shown to be an essential success criterion 28,42$] 43]$. For discontinuous service innovations, interaction with clients offers an opportunity to explain and convince customers of the value embodied in a new and unfamiliar service; for incremental products, highlighting on providing customers with a more satisfying experience; for example, offering more efficient problem solving, improved client training, or a more professional working relationship can be an essential basis for differentiating the new service from competitive 4446 .

\section{5 | Compatibility}

Compatibility is the degree to which an innovation is perceived as consistent with existing values, experience, and the needs of potential adopters ${ }^{399}$. Liu et al. ${ }^{47]}$ contended that an innovation diffuses more easily where such innovation appears to match the adopter's existing processes. Previous studies on innovation commercialization indicated that compatibility was one of the key factors that prevent innovation failure 17$]$ 39] 47 . The more compatibility the innovation with existing values, experience, and needs, the faster the adoption tends to be.

Other authors hold that compatibility is one of the key of market attractiveness and a precise definition of a customer need(s) ${ }^{42]}$. The new or emerging technologies usually take a long time to develop to the point where they solve customer problems 48 [49]. Compatibility is one of the key points to win the market. Technologies which are incompatible with customer values, system, and consumption pattern leads to purchase risks, particularly when the ultimate direction of the technology is unclear ${ }^{49}$. In the business-to-business sector, customer organizations that are responding to the need for cutting-edge innovation before the majority of the market accept the innovation can play an important role in the ultimate success of these types of new products 43 [50]. New products that are adaptation, refinements, and enhancements of existing products and/or delivery systems are often better performers because they build on established product platforms and because they leverage the known resources, skills, and identity of the firms 51 .

\section{6 | Complexity}

Complexity is the degree to which an innovation is perceived as relatively difficult to understand and use. Any innovation may be classified on the complexity-simplicity continuum. Complexity typically indicates a slower innovation adoption rate ${ }^{[52[53]}$, and may also create disutility through "feature fatigue" [54]. In the process of innovation diffusion, and innovation with complexities often entails potential customers to invest significant effort in learning to achieve promised benefits. Some individuals resist innovation because of their reluctance to undergo the necessary adjustment period. When people are confronted with a new product/service and are requested to undertake learning tasks to adopt it, the new task stress and the perception of less control over their lives produce resistance to innovation in concern. Specifically, innovation resistance occurs when consumers perceive the expected learning task as complex and difficult for innovation ${ }^{[55}$. The results of empirical research indicate that $41 \%$ of 
firms observe no return on their innovative products. In comparison, $48 \%$ of potential consumers delay purchases, and $30 \%$ of consumers return purchased technological innovation products due to consumer perception of product complexity.

These empirical studies reveal that a significant proportion of innovation commercialization failure resulting from the complexity of innovation. Rogers thus reiterated that an innovation's complexity could function as an inhibitor and is usually negatively related to innovation diffusion $\underline{39]}$.

\section{7 | Organizational Context}

The organizational context represents the factors internal to an organization influencing an innovation adoption and implementation ${ }^{15}$. The organizational context refers to the characteristics and resources of the firm, including linking structures between employees, intra-firm communication processes, firm size, and the number of slack resources ${ }^{[32]}$. Organizations play an important role in introducing innovation to the market. Sivadas and Dwyer ${ }^{[56}$ made their study comparison of organizational factors influencing new product success in the semiconductor and healthcare industry. Their study results show that new product development success is positively related to internal organization support among $R \& D$, marketing, manufacturing, and management support.

The success of the commercialization of innovation depends on the firm's new product strategy [28 [57]. In the case of highly innovative new products, it is their strategic fit which is essential as these ventures not only determine the firm's business success over a long run but considerably stretch its vital and scarce resource [12, 23] 28, 51$]$.

Another company-related success factor has to do with the type of innovation development culture that permeates the firm. Creating an entrepreneurial and team-oriented climate, with strong support and involvement from top management, is considered important for facilitating successful innovation by firms 30 . 58] . For a highly innovative new product venture, top management involvement is essential [48] 49 . Great management is empowered to move things forward quickly and effectively by activating functional involvement and minimizing expendable steps $[23$ [59].

This study chooses the following three organizational factors since they are widely referred to by prior research works 17$][23,35][56]$ 60]. They are organization culture of innovativeness, organization resource, and organization networking. These factors are highlighted because they significantly related to the success of innovation commercialization.

\section{8 $\mid$ Organizational Culture of Innovativeness}

Organizational culture is the pattern of the underlying assumption that a given group has invented, discovered, or developed in learning to cope with its problems of external adaptation and internal integration. It is widely recognized that innovation culture is related to increased organizational performance ${ }^{[48}$. A firm with innovativeness tends to promote change, creativity, and novelty to develop new products and processes ${ }^{61}$. Trot ${ }^{62}$ explained that long-term economic growth for a firm depends on the innovation capability. The development of innovation capability requires creativity and room to try out new ideas. This is usually accomplished in a cultural environment that explicitly recognizes the collective nature of innovation efforts. Empirical studies show that a firm's culture that is dedicated to innovation [17].

From a macro perspective, a firm with innovativeness encompasses the capacity of innovation to create a paradigm shift in an industry. From a micro view, a firm with innovativeness can be seen as the capacity to influence the firm's existing marketing resources, technological resources, skills, knowledge, capabilities, or strategy 60 . For several reasons, a firm with strong innovativeness can drive innovation strategy that leads to successful innovation commercialization. First, innovativeness provides a guideline for dealing with strategic issues, such as selecting the markets to enter and the required skills to develop. Second, innovativeness enables a firm to take advantage of the synergy between parallel innovation projects. Third, learning-by-doing can materialize the firm reap benefits of previously successful innovations and firm-specific skills that emanate from them [24.

\subsection{Organization Resources}

The Resource-Based View (RBV) is a well-known theory to determine the strategic resources available to a firm. The RBV asserts that firms sustain competitive advantages by deploying valuable resources that are superior, scarce, and inimitable 63 [64]. It includes capital, manufacturing facilities, and workforce requirements ${ }^{23}$. Commercializing an innovation not only requires tangible organization resources such as capital, manufacturing facilities, and financial resources but intangible ones, including 
technical competence, the experience of the industry, market knowledge, and close relationship with customers ${ }^{655}$. The more resources a firm allocates to innovation activities, the more likely it is to achieve successful innovation commercialization [10 [66].

For incremental new products, resources and strategic fit are also important. An excellent resource fit can lead to more efficient, error-free, and often more highly leveraged innovation; an excellent strategic fit is essential for planning and introducing innovation in which the firm can sustain its competitive advantage ${ }^{67]}$. Particularly in cases where services rely on distinctive, company facilities or resource, for example, a major operating system or a specialized team of experts; a high degree of fit can be incredibly advantageous from a cost, profit, and new product adoption perspective ${ }^{42] 68]}$.

\subsection{0 | Organization Networking}

Organization networking refers to the organization's pattern of relationships with other organizations in the same network [69]. The role, development, and performance of companies is described by their ability to develop relationships. The actors in a firm's networking include distributors, buyers, suppliers, research institutes, competitors, government agencies, industry associations. It has been widely acknowledged that networking plays a crucial role in the innovation commercialization route ${ }^{\text {70 }}$-72]. Diverse networking actors contribute to innovation commercialization in different ways ${ }^{[73]}$. For example, vertically related networking actors, such as customers, suppliers, and distributors, help a firm to stimulate innovative ideas and implement them. The horizontal actors, such as research institutions or partners beyond the traditional supply chain, facilitate bringing innovations to the market ${ }^{74}$.

Network relations could give the firm access to other firms' resources as complementary resources for innovation commercialization. Therefore organizational network means firms may create future demand and new market by integrating their complementary resources, products, and channel relationship through networking ${ }^{[74}$. Sharing resources and expertise to develop new products, achieve economies of scale, and gain access to new technology and market is the weapon to face the fierce competition 62 . Networking activities may serve as a basis for selling innovative products to customers with whom the company is not collaborating technologically. Network competence contributes to a company's innovation success directly, not only through increasing the degree of technological interweaving [50, 65] 73$]$. The rationale behind the positive impact is that through collaboration, more resources can be utilized in the development process, i.e., more personal power, a larger pool of technological facilities, larger quantity, and increased quality of information and ideas. Also, more innovation projects can be carried out due to more resources, which reduces the negative impact of failing individual developments ${ }^{[74}$.

\subsection{1 | Environment Context}

Environmental context is the external arena in which a firm conducts its business. The literature has identified several elements that contribute to environment context ${ }^{[15][17][5]}$. Among all environment-related factors, the current study deliberately chooses three, i.e., market demand, competitive pressure, and government policy. These factors are chosen due to their significant results and the highest number of citation from previous studies $[17[23]$ [3].

\subsection{2 | Market Demand}

Market demand refers to the presence of consumers with different needs and requirements on firms' innovation choices. Therefore, strong market demand is the prerequisite of any commercialization activities ${ }^{\mathbf{7}}$. Based upon an examination of some 567 innovations in five different industries, Myers and Marquis (1969) concluded that "recognition of demand is one of the most frequent consideration factors in innovation opportunity recognition." Cohen and Levin (1989) argued that market demand is more fundamental than other elements such as firm size or market concentration to achieve successful commercialization. Table 1 shows the factors considered for innovation commercialization.

Customers perceive the value of a product differently. The market demand is varied and heterogeneous. Hence, firms must understand their target customers and anticipate the dynamic preference of customers to meet market demand rapidly. In Mc Grath (1997), it is stated that a firm can test the market demand of an innovative product by asking the following questions: is there a need existing but not being satisfied by current products? Is the need prevalent? Does the innovative product that my firm develops satisfy the need? If yes, the higher the market demands, the higher value of the innovative product 
TABLE 1 Commercialization of an innovation consideration factors.

\begin{tabular}{|c|c|c|}
\hline Dimension & Factor & Definition \\
\hline \multirow[t]{3}{*}{ Technology } & $\begin{array}{l}\text { Relative } \\
\text { advantage }\end{array}$ & $\begin{array}{l}\text { The degree to which an innovation is perceived as being better than its } \\
\text { precursor. }\end{array}$ \\
\hline & Compatibility & $\begin{array}{l}\text { The degree to which an innovation is perceived as being consistent with } \\
\text { existing values, past experience, and the needs of potential adopters. }\end{array}$ \\
\hline & Complexity & $\begin{array}{l}\text { The degree to which an innovation is perceived as being difficult to } \\
\text { understand and use. }\end{array}$ \\
\hline \multirow[t]{3}{*}{ Organization } & $\begin{array}{l}\text { Organization } \\
\text { culture of } \\
\text { innovativeness }\end{array}$ & $\begin{array}{l}\text { A firm culture that promote change, creativity and novelty in order to } \\
\text { develop new product and processes. }\end{array}$ \\
\hline & $\begin{array}{l}\text { Organization } \\
\text { resource }\end{array}$ & $\begin{array}{l}\text { All of firm's assets and organizational attributes including knowledge } \\
\text { and processes controlled by them. }\end{array}$ \\
\hline & $\begin{array}{l}\text { Organization } \\
\text { networking }\end{array}$ & $\begin{array}{l}\text { The focal organization's pattern of relationships with other } \\
\text { organizations in the same network }\end{array}$ \\
\hline \multirow[t]{3}{*}{ Environment } & Market demand & $\begin{array}{l}\text { The presence of consumers with different needs and requirements on } \\
\text { firms' innovation choices. }\end{array}$ \\
\hline & $\begin{array}{l}\text { Competitive } \\
\text { pressure }\end{array}$ & $\begin{array}{l}\text { The intensity of competition coming from the same domain that a firm } \\
\text { in practice related to price, quality, service, or the salesforce or } \\
\text { distribution system. }\end{array}$ \\
\hline & $\begin{array}{l}\text { Government } \\
\text { policy }\end{array}$ & The rules set by government to impact a firm's innovation policy. \\
\hline
\end{tabular}

\subsection{3 | Competitive Pressure}

Competitive pressure refers to peer pressure coming from the same domain as a firm in practice. It reflects the intensity of competition in the marketplace concerning price, quality, service, or the sales force or distribution system [23]. Competitive pressure has long been recognized as a driving force of innovation; it further presses a company to seek a competitive edge through the success of innovation commercialization $[7$

Firms gain a competitive advantage in international competition through improvement, innovation, and upgrading. The commercialization of emerging technologies is characterized by intense competition in innovations. There is usually a substantial advantage to be the first innovators when the first mover's advantages are significant, and when the patent preemption is likely. Competition accelerates obsolescence and the rate at which innovators are disseminated, thereby curtailing their expected commercial lives and destroying their appropriable value. Past studies have assumed that if there is no competition in innovation activities, the state of the art of today's technological progress in the future, and that the proprietary rights of current technologies are guarantees forever.

\subsection{Government Policy}

Government policy is a powerful force to impact a firm's innovation policy ${ }^{33}$. Innovation policies can emphasize basic research and technology development (e.g., public funding of basic research), exploitation of research infrastructure (e.g., universityindustry collaboration), support of industrial technology development (e.g., tax subsidies for R\&D), technology adoption, and technical standardization. Government authority attempts to create an environment conducive to innovation through legal mechanisms such as tax codes, patent law, and antitrust regulations. The government, primarily at the national level, provides technology infrastructure that leverages the innovation process. Through its actions providing technology infrastructure, the government supports mechanisms, institutions, and platforms to lessen innovation barriers that cause market failure for investments in all stages of technology-based economic activity ${ }^{75 .}$. Technology policy was defined as policies that are intended to influence firms decisions to develop, commercialize, or adopt new technologies. Innovation policy refers to policies intended to influence public and private organizations' behavior in the development and commercialization of new technologies.

Governments have taken various policy measures to promote innovative activities to reap economic and social benefits from technological progress ${ }^{176}$. There is a tendency in many countries that the government authorities seek to nourish innovations by means of establishing science parks and business incubators. Whether such parks and incubators are the results of a "natural" outgrowth of research centers or spin-offs from incumbent enterprises, the phenomenon has shaped an important mode of innovation commercialization ${ }^{[42]}$. The example of government policy that successfully supports innovation commercialization is in U.S Small Business Innovation Research (SBIR) program. In the SBIR program, the government provides financial capital, 


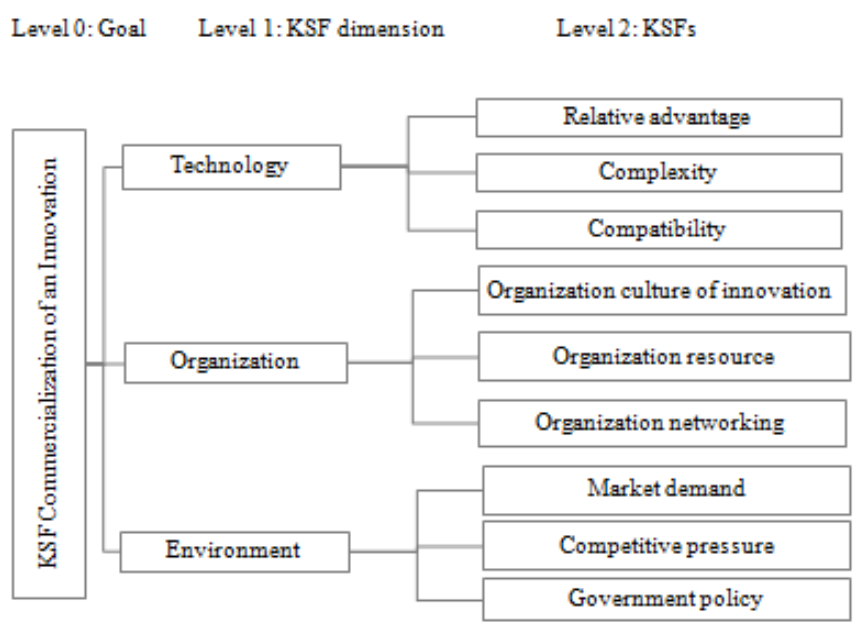

FIGURE 2 The two-level hierarchy of the key successful factors for innovation commercialization.

is a decision-maker, is an organizer and coordinator of economic resources, and is an allocator of resources among alternative uses.

\section{3 | MATERIAL AND METHOD}

Thomas L. AHP originally devised the Analytic Hierarchy Process (AHP) is a structured technique for organizing and analyzing complex decisions based on paired comparisons of both projects and criteria. These inputs are converted into scores that are used to evaluate each of the possible alternatives.

The AHP is a powerful management science tool that has proven useful in structuring complex multi-person, multi-criterion decisions in business and economics. The advantages of AHP to the user include its reliance on easily obtained managerial judgment data, its ability to reconcile differences (inconsistencies) in managerial judgments and perceptions, and the existence of easy-to-use commercial software (i.e. "Expert Choice") that implements the AHP ${ }^{[23}$. The strength of the AHP method lies in its ability to structure complex, multi-person, multi-attribute, and multi-period problem hierarchically. Thus, it has been discussed in a wide variety of decision situations in fields such as business planning, resource allocation, priority setting, and selection among alternatives. This AHP method can give reasonable approximation when the decision maker's judgments are consistent.

The first stage is grouping the success factors from previous studies [17 [19]23] 24] [28] 35], and put their success factors into TOE framework. The process of choosing the dimension involved scholar opinions. The following three questions were asked to the expert:

Q1 Which KSFs do you think are more appropriate for the commercialization of an innovation?

Q2 Which KSFs are fractional but related enough to be combined into one?

Q3 Which KSFs are similar and can be grouped into categories in light of TOE?

\section{1 | Research Survey}

Figure 2 shows the hierarchy of KSF for innovation commercialization. The hierarchy is designed as two-level hierarchy. Inline with the hierarchy, we designed a questionnaire complying with the AHP format. The questionnaire was distributed to 16 selected members from 2 companies; 8 marketing experts from PT. Pertamina, which represents the petroleum industry in Indonesia and eight marketing and promotion experts from PT.Bio Farma represents the pharmaceutical industry, and all members had more than ten years of working experience in their industry. The chosen members have been working in the industry for at least more 


\section{Synthesis with respect to:}

Goal: Commercialization of an Innovation

Overall Inconsistency $=.07$

Relative advantage

Compatibility

Market demand

Organization networking

Organization culture of innovative..

Organization resource

Complexity

Competitive pressure

Government policy

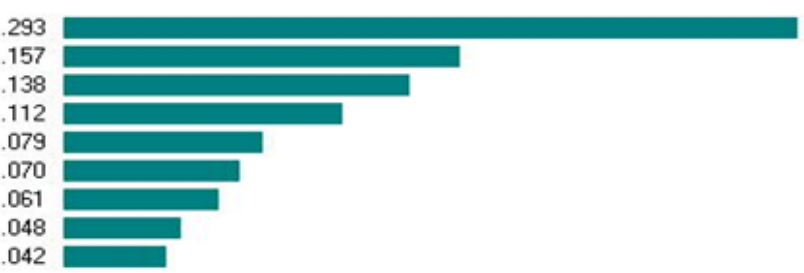

FIGURE 3 The consistency ratio from AHP result.

TABLE 2 Weights and ranks of the six criterion groups and 22 sub-criteria.

\begin{tabular}{|c|c|c|c|c|c|c|}
\hline Criteria & $\begin{array}{c}\text { Local } \\
\text { Weight }\end{array}$ & Rank & Factors & $\begin{array}{c}\text { Local } \\
\text { Weight }\end{array}$ & $\begin{array}{l}\text { Global } \\
\text { Weight }\end{array}$ & Rank \\
\hline \multirow[t]{3}{*}{ Technology } & 0.539 & 1 & Relative advantage & 0.573 & 0.309 & 1 \\
\hline & & & Complexity & 0.119 & 0.064 & 5 \\
\hline & & & Compatibility & 0.308 & 0.166 & 2 \\
\hline \multirow[t]{3}{*}{ Organization } & 0.207 & 3 & $\begin{array}{l}\text { Organization network- } \\
\text { ing }\end{array}$ & 0.430 & 0.089 & 4 \\
\hline & & & $\begin{array}{l}\text { Organization culture of } \\
\text { innovativeness }\end{array}$ & 0.301 & 0.062 & 6 \\
\hline & & & Organization resource & 0.269 & 0.056 & 7 \\
\hline \multirow[t]{3}{*}{ Environment } & 0254 & 2 & Market demand & 0.608 & 0.155 & 3 \\
\hline & & & Competitive pressure & 0.210 & 0.053 & 8 \\
\hline & & & Government policy & 0.183 & 0.046 & 9 \\
\hline
\end{tabular}

than eight years. The two companies are chosen based on their performance and reputation as a successful high-technology based industry in Indonesia.

The survey was conducted for approximately four months, starting from March to June 2018. Initially, we submitted a research proposal to be reviewed by both companies. The official proposal was sent via email. Furthermore, the questionnaire was given directly to both companies in Indonesia. Correspondence was done face to face, via phone also via email. Results from the questionnaire were sent gradually over two months via email. The survey allows the selected members to give the relative importance ranking of the aforementioned KSF each dimension and factors.

\section{4 | RESULTS AND DISCUSSION}

After the pair-wise comparison process is completed, and an initial decision matrix is achieved, the initial matrix is normalized. As shown in Figure 3, in this study, overall CR is 0.07 , which fell within the acceptable level of 0.10, as recommended by Saaty $[18$. This shows that the survey respondents have assigned their weights consistently after examining the priorities of success factors of commercialization for new technology products

As shown in Table 2, the criterion group of technology has the highest rank, weighing 53,9\%. More than half of the weight falls into the technology factor. This result is relevant to prior research. In the successful new product commercialization, technology is one of the most commonly cited success factors ${ }^{[26]}$. Environment factors rank below the technology factor with $25,4 \%$; this shows that environmental factors also embodied significant role for a successful new product, supported by a literature review that emphasized the significant role of the market research, which includes market, customer, and competitor analysis in stimulating the need for a new product. Most of the literature pointed out the impotence of product technology and market demand and put the organization factors below these two factors, which explained why the organization factor placed third among the TOE framework with $20,7 \%$. 
As shown in Figure 4, the criterion group of technology has the highest rank, with weighting 53,9\%. More than half of the weight falls into the technology factor. This result is relevant to prior research. In the successful new product commercialization, technology is one of the most commonly cited success factors.

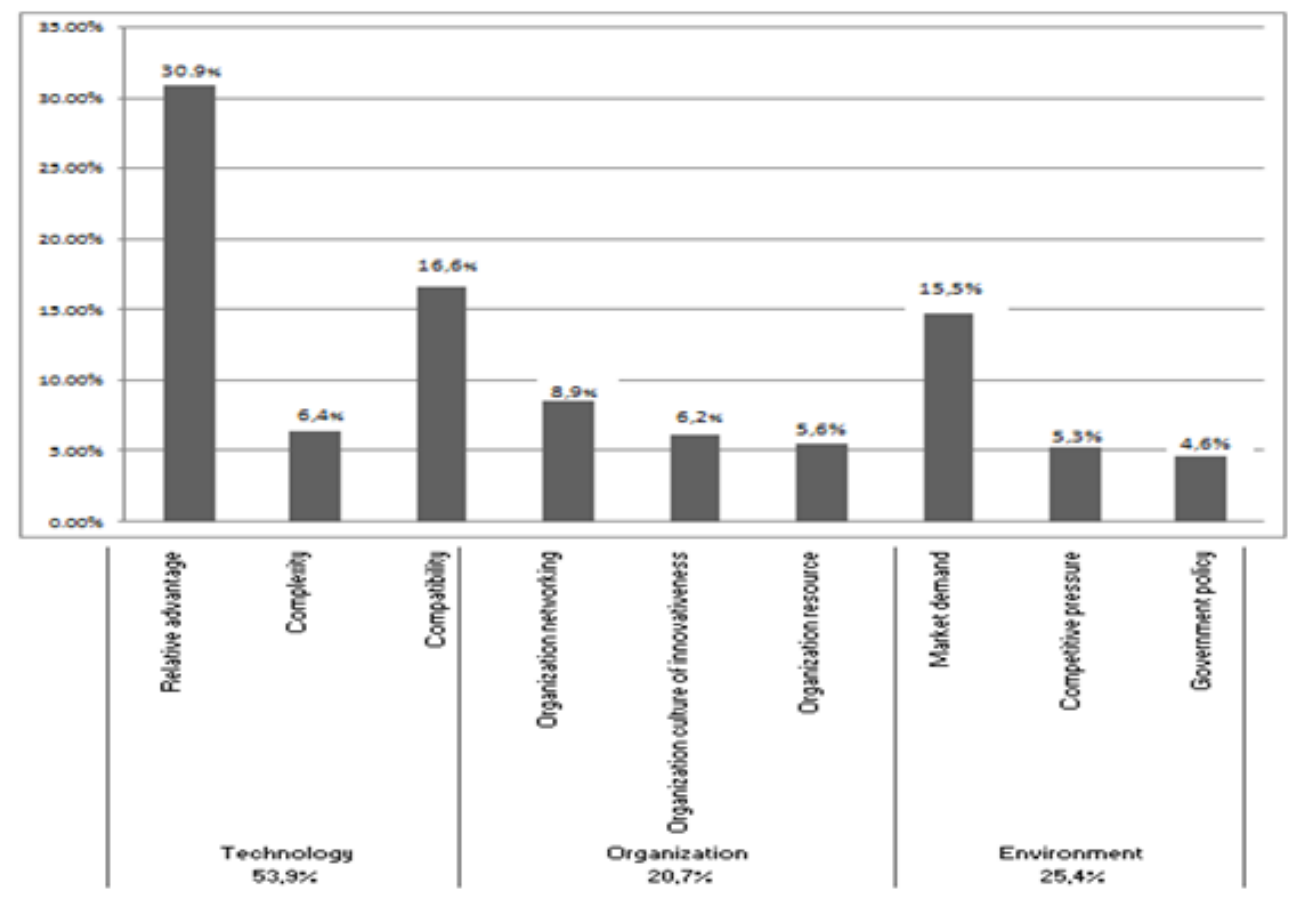

FIGURE 4 Histogram of weights against 9 sub-criteria in 3 criterion groups.

The results of our analysis could provide an assessment framework for the commercialization of new technology products. We suggest a new technology product assessment model that can be practically applied by experts to minimize the market and technology uncertainties and to increase the decisions' effectiveness.The criterion group of technology has the highest rank, with weighting $53,9 \%$. It suggest that in the successful new product commercialization, technology is one of the most commonly cited success factors.

Environment factors rank below the technology factor with 25,4\%; this shows that environmental factors also embodied significant role for the successful new product, supported by a literature review that emphasized the significant role of the market research, which includes market, customer, and competitor analysis in stimulating the need for a new product. Most of the literature pointed out the impotence of product technology and market demand and put the organization factors below these two factors, which explain why the organization factor placed third among the TOE framework with 20,7\%.

This result can also explain in the technology-driven product. Where innovation has been induced by technological capability rather than expressed market need, the concept of technology-push applies ${ }^{[34}$. For years, scholars have argued about two kinds of successful market-driven; technology-push and demand-pull [50]. Market-pull driven strategy predominates because they aim to improve existing product lines according to consumer market trends. Most technical innovations were driven by science and technology, the role of demand, and more broadly of the market and social forces were complementary in that respect.

However, more recent studies believe that many technological innovations have their origin in science and technology but still need a market and the related complementary assets to be successfully commercialized. It is assumed that both strategies, technology push, and market pull, are equally important to all kinds of organizations. It is believed that 'technology-push' and 'demand-pull' are complementary, rather than contradictory, factors determining the success of innovation. This study found 
that alongside technology factors (relative advantage and compatibility), environmental factors (market demand) also received a higher score than remaining factors.

The overall result shows that Technology's factors are more appealing in Indonesia's high-tech industry than Environment factors like market demand. This can be explaining by the light-emitting diode (LED) lighting in Korea as an illustrative example because it coincides with features of companies adopting the technology-push strategy. Most consumers may be ignorant about laser medical devices because the specifications of the relevant technology embodied in products are challenging to understand, such as principles and components. Because it is challenging to acquire customer requirements, new product development is led not by customer needs but, instead, by advances in technology and inventors. Although the proposed approach is based on technology, and consumers are not familiar with technology, they would be closely associated with technology. Potential and possible concepts of products and markets are extracted from the technological specification. Thus, firms in the solar LED lighting field easily choose a technology-driven strategy more than a market-pull strategy for their R\&D planning.

The results of this study might give more insight for managers to have a better strategy for successfully launch their new product, especially in the Indonesian market. The top-level of the KSF hierarchy, within the technology dimension, the success of new product commercialization depends heavily on the relative advantage and compatibility of the product. Firms must be able to convince the market that their new product gives advantages over other available products 39 . The new technologies also have to compatible with Indonesian customer value. Compatibility is one of the key points to win the market. Ease of use of the innovation facilitates its diffusion and speeds-up its adoption. Running trials reduces customer uncertainty and reinforces positive attitudes, and thus eases adoption ${ }^{9}$. Customers evaluate the relative advantage and therefore need to be convinced about the potential benefits ${ }^{39}$. The more observable such benefits are, and the more compatible the innovation is with existing values, experiences, and needs, the faster the adoption tends to be. Other than the relative advantage and compatibility of the product, this study shows that the market demand factor is nearly as crucial as product compatibility. Firms must understand that consumer needs are subject to change over time, as are the specific ways in which consumers seek to satisfy these needs through the purchase and consumption of particular products ('demand'). Such changes may occur as a result of demographic, socio-economic, and cultural changes in society.

\section{5 | CONCLUSION}

This study aims to analyze the critical success factors for commercializing innovations produced by R\&D in Indonesia. It used TOE framework to investigate the determinants of innovation commercialization. The results of our analysis could provide an assessment framework for the commercialization of new technology products. We suggest a new technology product assessment model that can be practically applied by experts to minimize the market and technology uncertainties and to increase the decisions' effectiveness. As shown in Figure 4, the criterion group of technology has the highest rank, with weighting 53,9\%. In the successful new product commercialization, technology is one of the most commonly cited success factors.

Environment factors rank below the technology factor with 25,4\%; this shows that environmental factors also embodied significant role for the successful new product, supported by a literature review that emphasized the significant role of the market research, which includes market, customer, and competitor analysis in stimulating the need for a new product. Most of the literature pointed out the impotence of product technology and market demand and put the organization factors below these two factors, which explain why the organization factor placed third among the TOE framework with 20,7\%. Most technical innovations were driven by science and technology, the role of demand, and more broadly of the market and social forces were complementary in that respect. However, more recent studies believe that many technological innovations have their origin in science and technology but still need a market and the related complementary assets to be successfully commercialized.

\section{References}

1. Lee S, Yoon B, Park Y. An Approach to Discovering New Technology Opportunities: Keyword-Based Patent Map Approach. Technovation 2009 jun;29(6-7):481-497.

2. Ali A. Pioneering Versus Incremental Innovation: Review and Research Propositions. The Journal of Product Innovation Management 1994 jan;11(1):46-61. 
3. Lynn GS, Morone JG, Paulson AS. Marketing and Discontinuous Innovation: The Probe and Learn Process. California Management Review 1996;38(3):8-37.

4. Mitchell VW, Greatorex M. Risk Perception and Reduction in the Purchase of Consumer Services. Service Industries Journal 1993 oct;13(4):179-200.

5. Zahra SA, Nielsen AP. Sources of Capabilities, Integration and Technology Commercialization. Strategic Management Journal 2002 may;23(5):377-398.

6. Tidd J, Bessant J, Pavitt K. Managing Innovation: Integrating Technological, Market and Organizational Change. 3 ed. Hoboken: John Wiley; 2005.

7. Gatignon H, Robertson TS, Fein AJ. Incumbent Defense Strategies Against New Product Entry. International Journal of Research in Marketing 1997;14(2):163-176.

8. Kohli AK, Jaworski BJ, Kumar A. MARKOR: A Measure of Market Orientation. Journal of Marketing Research 1993 nov;30(4):467. https://www.jstor.org/stable/3172691

9. Ruekert RW. Developing A Market Orientation: An Organizational Strategy Perspective. International Journal of Research in Marketing 1992 aug;9(3):225-245.

10. Gadenne D. Critical Success Factors for Small Business: An Inter-Industry Comparison. International Small Business Journal 1998;17(1):36-56.

11. Simpson M, Padmore J, Newman N. Towards A New Model of Success and Performance in SMEs,. International Journal of Entrepreneurial Behaviour \& Research 2012 may;18(3):264-285.

12. Koschmider A, Song M, Reijers HA. Social Software for Business Process Modeling. Journal of Information Technology 2010 sep;25(3):308-322.

13. Butler T, Fitzgerald B. Unpacking The Systems development Process: An Empirical Application of The CSF Concept in A Research Context. Journal of Strategic Information Systems 1999 dec;8(4):351-371.

14. Dobbs M, Hamilton RT. Small Business Growth: Recent Evidence and New Directions. International Journal of Entrepreneurial Behaviour and Research 2007;13(5):296-322.

15. Tornatzky LG, Fleischer M, Chakrabarti AK. The Process of Technology Innovation. Lexington, Mas: Lexingt. Books; 1990.

16. Akyildiz B, Kadaifci C, Topcu I. A Decision Framework Proposal for Customer Order Prioritization: A Case Study for A Structural Steel Company. In: International Journal of Production Economics, vol. 169 Elsevier; 2015. p. 21-30.

17. Van der Panne G, Beers CV, Kleinknech A. Success and Failure of Innovation: A Literature Review. International Journal of Innovation Management 2003 sep;7(3):309-338.

18. T L Saaty. The Analytic Hierarchy Process, Planning, Piority Setting, Resource Allocation. New York: Mc Graw Hill; 1980.

19. Teece DJ. Profiting from Technological Innovation: Implications for Integration, Collaboration, Licensing and Public Policy. Research Policy 1986 dec;15(6):285-305.

20. C F, R D. Critical Success Factors for Directors in The Eighties. Business Horizons 1982;25(3):14-18. https://econpapers.

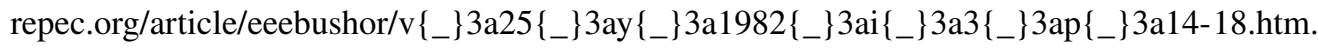

21. Ohmae K. The Strategic Triangle: A New Perspective on Business Unit Strategy. European Management Journal 1982 jun;1(1):38-48.

22. Schumpeter JA. Business Cycles: A Theoretical, Historical, and Statistical Analysis of The Capitalist Process. New York: McGraw-Hill; 1939. 
23. Montoya-Weiss MM, Calantone R. Determinants of New Product Performance: A Review and Meta-Analysis. Journal of Product Innovation Management: An International Publication Of The Product Development \& Management Association 1994 nov;11(5):397-417.

24. Rothwell R, Freeman C, Horlsey A, Jervis VTP, Robertson AB, Townsend J. SAPPHO Project. Research Policy 1974 nov;3(3):258-291. https://linkinghub.elsevier.com/retrieve/pii/0048733374900109.

25. Kim CH, Ko CR. Group Dynamics of Success and Failure Factors of Technology Commercialization in Small Technology. Asian Journal of Innovation and Policy 2014 may;3(1):25-49.

26. Atuahene-Gima K. Market Orientation and Innovation. Journal of Business Research 1996 feb;35(2):93-103.

27. Benedetto CA. Identifying the Key Success Factors in New Product Launch. Journal of Product Innovation Management 1999 nov;16(6):530-544.

28. Cooper RG. Third-Generation New Product Processes. Journal of Product Innovation Management: An International Publication of the Product Development \& Management Association 1994 jan;11(1):3-14.

29. Langerak F, Hultink EJ, Robben HSJ. The Impact of Market Orientation, Product Advantage, and Launch Proficiency on New Product Performance and Organizational Performance. Journal of Product Innovation Management 2004 mar;21(2):79-94.

30. Parry ME, Song XM. Identifying New Product Successes in China. The Journal of Product Innovation Management 1994 jan;11(1):15-30.

31. Conn RL, Cosh A, Guest PM, Hughes A. The Impact on UK Acquirers of Domestic, Cross-Border, Public and Private Acquisitions. Journal of Business Finance and Accounting 2005 jun;32(5-6):815-870.

32. Dwivedi YK, Schneberger SL, Wade MR. Information Systems Theory: Explaining and Predicting Our Digital Society. 2 ed. New York: Springer Science+Business Media, LLC, 2012.; 2012.

33. Hwang BN, Huang CY, Wu CH. A TOE Approach to Establish A Green Supply Chain Adoption Decision Model in The Semiconductor Industry. Sustainability (Switzerland) 2016;8(2):168.

34. Oliveira T, Martins MF. Literature Review of Information Technology Adoption Models at Firm Level. Electronic Journal of Information Systems Evaluation 2011;14(1):312-322.

35. Henard DH, Szymanski DM. Why Some New Products are More Successful than Others. Journal of marketing Research 2003;38(3):362-375.

36. Prais SJ. E .Mansfield. Industrial Research and Technological Innovation: An Econometric Analysis. The Economic Journal 1968;78(311):676-679.

37. Cusumano MA, Takeishi A. Supplier Relations and Management: A Survey of Japanese, Japanese-Transplant, and U.S. Auto Plants. Strategic Management Journal 1991 nov;12(8):563-588.

38. Edler J, Georghiou L. Public Procurement and Innovation-Resurrecting The Demand Side. Research Policy 2007 sep;36(7):949-963.

39. M Rogers E. Diffusion of Preventive Innovations. Addictive behaviors 2002;27(6):989-993.

40. Sia CL, Teo HH, Tan BCY, Wei KK. Effects of Environmental Uncertainty on Organizational Intention to Adopt Distributed Work Arrangements. IEEE Transactions on Engineering Management 2004 aug;51(3):253-267.

41. Hauser J, Tellis GJ, Griffin A. Research on Innovation: A Review and Agenda for Marketing Science. Marketing Science 2006 nov;25(6):687-717.

42. De Brentani U, Ragot E. Developing New Business to-Business Professional Services: What Factors Impact Performance? Industrial Marketing Management 1996 nov;25(6):517-530. 
43. Storey C, Easingwood CJ. The Augmented Service Offering: A Conceptualization and Study of Its Impact on New Service Success. Journal of Product Innovation Management: AN INTERNATIONAL PUBLICATION OF THE PRODUCT DEVELOPMENT \& MANAGEMENT ASSOCIATION 1998 jul;15(4):335-351.

44. Berry LL. Relationship Marketing of Services-Growing Interest Emerging Perspectives. Journal of the Academy of Marketing Science 1995;23(4):236-245.

45. Gummesson E. The New Marketing-Developing Long-Term Interactive Relationships. Long Range Planning 1987 aug;20(4):10-20.

46. Zeithaml VA. Consumer Perceptions of Price, Quality, and Value: A Means-End Model and Synthesis of Evidence. Journal of Marketing 1988 jul;52(3):2-22.

47. Liu X, Hodgkinson IR, Chuang FM. Foreign Competition, Domestic Knowledge Base and Innovation Activities: Evidence from Chinese High-Tech Industries. Research Policy 2014 mar;43(2):414-422.

48. O'Connor GC. Market Learning and Radical Innovation: A Cross Case Comparison of Eight Radical Innovation Projects. Journal of Product Innovation Management: AN INTERNATIONAL PUBLICATION OF THE PRODUCT DEVELOPMENT \& MANAGEMENT ASSOCIATION 1998 mar;15(2):151-166.

49. Veryzer Jr RW. Discontinuous Innovation and the New Product Development Process. Journal of Product Innovation Management: an international publication of the product development \& management association 1998 jul;15(4):304-321.

50. Von Hippel E. Lead Users: A Source of Novel Product Concepts. Management Science 1986;32(7):791-805.

51. Khurana A, Rosenthal SR. Towards Holistic Front Ends in NPD In New Product Development. Journal of Product Innovation Management: An International Publication of the Product Development \& Management Association 1998 jan;15(1):57-74.

52. Jaw C, Yu O, Gehrt K. The Roles of User Psychological Perceptions on the Adoption of Web-Based Service Innovations. In Proceedings of 19th International Business Research Conference 2012 nov;.

53. Meuter ML, Bitner MJ, Ostrom AL, Brown SW. Choosing Among Alternative Service Delivery Modes: An Investigation of Customer Trial of Self-Service Technologies. Journal of marketing 2005 aug;69(2):1861-83.

54. Thompson DV, Hamilton RW, Rust RT. Feature Fatigue: When Product Capabilities Become Too Much of a Good Thing. Journal of Marketing Research 2005;42(4):431-442. https://www.msi.org/reports/ feature-fatigue-when-product-capabilities-become-too-much-of-a-good-thing/

55. Luce MF, Payne JW, Bettman JR. Emotional Trade-Off Difficulty and Choice. Journal of Marketing Research 1999;36(2):143-159.

56. Sivadas E, Dwyer R. An Examination of Organizational Factors Influencing New Product Success in Internal and AllianceBased Processes. Journal of Marketing 2000;64(1):31-49.

57. Griffin A, Page AL. PDMA Success Measurement Project: Recommended Measures for Product Development Success and Failure. AN INTERNATIONAL PUBLICATION OF THE PRODUCT DEVELOPMENT \& MANAGEMENT ASSOCIATION 1996 nov;13(6):478-496.

58. Wilemon AKG, L D. Accelerating the Development of Technology-Based New Products. Calif Manage Rev 2015;

59. Thwaites D. Organizational Influences on The New Product Development Process in Financial Services. Journal of Product Innovation Management 1992 dec;9(4):303-313. http://doi.wiley.com/10.1111/1540-5885.940303.

60. Garcia R, Calantone R. A critical Look at Technological Innovation Typology and Innovativeness Terminology: A Literature Review. Journal of Product Innovation Management: An international publication of the product development \& management association 2002 mar;19(2):110-132. 
61. Lumpkin GT, Dess GG. Clarifying The Entrepreneurial Orientation Construct and Linking it to Performance. Academy of Management Review 1996;21(1):135-172.

62. Trott P. The Role of Market Research in The Development of Discontinuous New Products. European Journal of Innovation Management 2001 sep;4(3):117-126.

63. Barney JB. Strategic Factor Markets: Expectations, Luck, and Business Strategy. Management Science 1986 oct;32(10):1231-1241.

64. Roberts PW, Dowling GR. Corporate Reputation and Sustained Superior Financial Performance. Strategic Management Journal 2002;23(12):1077-1093.

65. Gadde LE, Huemer L, Hakansson H. Strategizing in Industrial Networks. Industrial Marketing Management 2003 jul;32(5):357-364.

66. Utterback JM, Allen TJ, Hollomon JH, Sirbu MA. The process of innovation in five industries in Europe and Japan. IEEE Transactions on Engineering Management 1976;EM-23(1):3-9.

67. Clark KB, Wheelwright SC. Managing New Product and Process Development Text and Cases. 3 ed. New York: Maxwell Macmillan; 1992.

68. Johne A, Storey C. New Service Development: A Review of the Literature and Annotated Bibliography. Eur J Mark 1998;32(3):184-251.

69. Gulati R, Zajac EJ. Commentary on'Alliances and Networks' by R. Gulati. Strategic Management Journal 1998;19:319-321. https://www.jstor.org/stable/3094068

70. Fieser JB. Technology and Economic Development: The Dynamics of Local, Regional, and National Change. Economic Geography 1993;69(1):94-96.

71. Hite JM, Hesterly WS. The Evolution of Firm Networks: from Emergence to Early Growth of the Firm. Strategic Management Journal 2001 mar;22(3):275-286.

72. Freel MS. Sectoral Patterns of Small Firm Innovation, Networking and Proximity. Research Policy 2003 may;32(5):751770 .

73. Ritter T, Gemünden HG. Network Competence: Its Impact on Innovation Success and Its Antecedents. Journal of Business Research 2003 sep;56(9):745-755.

74. Moller K, Rajala A. Rise of Strategic Nets - New Modes of Value Creation. Industrial Marketing Management 2007 oct;36(7):895-908.

75. Link AN, Scott JT. Government as Entrepreneur: Evaluating the Commercialization Success of SBIR Projects. Research Policy 2010 jun;39(5):589-601.

76. Gassmann H. Globalisation and Industrial Competitiveness. OECD Observer 1995; 197:38. https://www.researchgate.net/ publication/298609303\{_\}Globalisation $\left\{_{-}\right\}$and $\left\{_{-}\right\}$industrial $\left\{_{-}\right\}$competitiveness

How to cite this article: Mawaddah P., Huang B.N., Chang C.H., (2020), Analysis of the Key Success Factors for Commercializing Innovation, IPTEK The Journal of Technology and Science, 31(2):111-126. 